\title{
Eficacia y seguridad del policresuleno en el aclaramiento del virus del papiloma humano (VPH)
}

\section{Efficacy and safety of polyresullen in the clearance of human papillomavirus (HPV)}

Espitia De La Hoz ${ }^{1}$

Recibido para publicación: - Aprobado para publicación:

\begin{abstract}
RESUMEN
Objetivo: Evaluar la eficacia y seguridad del policresuleno como coadyuvante en el aclaramiento del virus del papiloma humano, en mujeres con lesión escamosa intraepitelial de bajo grado (LEI-BG). Material y métodos: ensayo clínico aleatorizado, controlado, triple ciego, en una población de 416 participantes, entre 2017 y 2019. Se incluyeron mujeres mayores de 30 años que no estaban en la menopausia, a las cuales se les diagnosticó lesión escamosa intraepitelial de bajo grado (LEI-BG) positivas para VPH, a través de colposcopía, biopsia y tamizaje. Un grupo ( $« 1 »: \mathrm{n}=207)$ recibió policresuleno, el grupo «2» $(n=209)$ recibió placebo. Resultados: la edad media fue de 34,62 $\pm 10,89$ años. El policresuleno fue efectivo para el control del VPH, lográndose una negativización del $89,85 \%$ frente al $64,59 \%$ del placebo $(p<0,001)$ a los 12 meses. La incidencia de efectos secundarios fue la siguiente: sequedad vaginal $(7,24 \%)$ y la descarga de fragmentos de membrana mucosa $(8,69 \%)$ en el grupo policresuleno frente al $6,69 \%$ y $8,13 \%$, respectivamente, del grupo placebo $(p=0,051)$. Conclusiones: La mejoría del $89,85 \%$ de la LEI-BG positivas para $\mathrm{VPH}$, en mujeres mayores de 30 años, significativa que el uso del policresuleno es una efectiva y segura opción terapéutica.
\end{abstract}

Palabras clave: Displasia del Cuello del Útero; Eficacia; Mujeres; Seguridad; Terapéutica.

\begin{abstract}
Objective: To evaluate the efficacy and safety of polyresullen as an adjuvant in the clearance of human papilloma virus, in women with low-grade squamous intraepithelial lesion (LEIBG). Material and methods: randomized, controlled, triple blind clinical trial, in a population of 416 participants, between 2017 and 2019. Women older than 30 years who were not in menopause, who were diagnosed with low squamous intraepithelial lesion, were included. grade (LEI-BG) positive for HPV, through colposcopy, biopsy and screening. One group (" 1 ": $n=207)$ received polyresullen, group " 2 " $(n=$ 209) received placebo. Results: the mean age was $34.62 \pm$ 10.89 years. Polycresullen was effective for controlling HPV, achieving a negative of $89.85 \%$ compared to $64.59 \%$ of placebo $(p<0.001)$ at 12 months. The incidence of side effects was as follows: vaginal dryness $(7.24 \%)$ and discharge of mucous membrane fragments $(8.69 \%)$ in the polyresulin group compared to $6.69 \%$ and $8.13 \%$, respectively, of the placebo group $(p=0.051)$. Conclusions: The $89.85 \%$ improvement of the HPV-positive LEI-BG in women older than 30 years, significant that the use of polyresullen is an effective and safe therapeutic option.
\end{abstract}

Key words: Uterine Cervical Dysplasia; Efficacy; Women; Safety; Therapeutics.

\section{Citación (Vancouver)}

Eficacia y seguridad del policresuleno en el aclaramiento de virus del papiloma humano (VPH). Rev Avances en Salud; 2021. (5)2:8-14. DOI: 


\section{INTRODUCCIÓN}

EEl virus del papiloma humano (VPH) es un virus de $A D N$, perteneciente a la familia Papilomaviridae, de doble cadena, no encapsulado, de cápside proteica de simetría icosaédrica; se reproduce en el núcleo de las células epiteliales (1-3). En su genoma tiene 8000 pares de bases de longitud. Se encuentra divido en tres regiones: una región reguladora no codificada, Ilamada región larga control (LCR, del inglés Long Control Región), una región de genes de expresión temprana $(E$ early-temprana / la representan E1, E2, E5, E6, E7) y una región que contiene genes de expresión tardía (L late-tardía / L1 y L2), que son críticas para la infección del huésped $(4,5)$.

Hoy, alrededor de 150 tipos de VPH son reconocidos, identificados y subdivididos, según su potencial de malignidad como virus de alto riego, riesgo intermedio y riesgo bajo; aproximadamente 35 a 40 tipos de poseen la capacidad de infectar el epitelio anogenitales en humanos, aunque no todos son oncogénicos. Hay al menos 17 tipos de alto riesgo $(16,18,31,33,35,39,45,51,52$, $55,56,58,59,68,73,82$ y $83(6,7)$. Se cree que la infección persistente con $\mathrm{VPH}$ de alto riesgo puede provocar neoplasias malignas en cooperación con otros oncogenes. Los tipos 16 y 18 son los genotipos más frecuentemente asociados a cáncer cervical, vulvar, de pene y anal; mientras que los tipos 6 y 11 están asociados al desarrollo de lesiones benignas como verrugas y condiloma acuminado (6-8).

La infección por el VPH, está catalogada como una infección de transmisión sexual (ITS), que afecta, en la mayoría de los casos, a los órganos genitales (9). Su gran importancia radica en la relación que tiene con las lesiones pre-neoplásicas y del cáncer de cuello uterino, así como de otras neoplasias en genitales y mucosas (10).
A nivel mundial el VPH 16 y 18 son los responsables del $70 \%$ de todos los cánceres de cuello uterino, del $41-67 \%$ de las lesiones cervicales de alto grado y hasta del $32 \%$ de las lesiones cervicales de bajo grado $(10,11)$; sin embargo, otros tipos de alto riesgo corresponden al VPH 31, 33, 45 y 58 (12)

La prevalencia de la infección por VPH varía dependiendo tanto del método diagnóstico como de la población en estudio. En mujeres con citología normal la prevalencia del VPH alcanza el $10,2 \%$ a nivel global, $22,4 \%$ en África, $13 \%$ en América, 8,2\% en Europa y un 7,9\% en Asia (13).

En América Latina y el Caribe, el 82,5\% de las lesiones neoplasias intraepiteliales cervicales (NIC) grado 2 y 3, y el $89 \%$ de los cánceres de cuello uterino son positivos para $\mathrm{VPH}$; la proporción atribuible a los genotipos 16 y 18 es similar a la publicada mundialmente. Las cifras constituyen la infección por VPH, como un grave problema de salud pública (14). La elevada prevalencia de esta infección, la relaciona con la conducta sexual de cada individuo (15).

La transmisión del VPH se da usualmente por el contacto directo, facilitando la transferencia entre las células epiteliales. Las vías de transmisión suelen ser: por contacto sexual, sangre, vía perinatal, infección vertical, etc. (16).

Los factores de riesgo relacionado con la infección del VPH destacan: promiscuidad, inicio temprano de relaciones sexuales, embarazo precoz, multiparidad, antecedente de ITS, tabaquismo, deficiencias nutricionales, factores genéticos, etc. (17). El primer embarazo a edades tempranas, así como la multiparidad y tener múltiples parejas sexuales, son los factores de riesgo más fuertemente asociados al desarrollo de cáncer cérvico-uterino (17-19).

El diagnóstico del VPH puede ser clínico, inmunológico citológico, histológico, histoquímico o por procedimientos de 
biología molecular (20). La aplicación de marcadores biológicos, así como el análisis de la frecuencia de los genotipos virales sirve de apoyo a la citología cervical, dado que aumenta la sensibilidad diagnóstica y proporciona el tipo viral infectante (21).

A la fecha no existe un medicamento que sea única y específicamente para el tratamiento de la infección delVPH. Entrelas opciones disponibles se encuentran químicos (citotoxicidad química), tópicos (ácido tricloroacético), antimetabolitos (5-fluoracilo) y agentes antimicóticos (podofilina-podofilotoxina), antivirales e inmunorreguladores (interferón-alfa, imiquimod y el ácido glicirricínico) de utilidad en las verrugas. Los métodos para destrucción del tejido dañado: crioterapia, electrocoagulación diatérmica, termocoagulación, vaporización con láser, Asa dérmica y conización con bisturí e histerectomía

La historia natural del cáncer cérvico-uterino implica la progresión gradual por etapas intraepiteliales preinvasoras: neoplasias intraepiteliales (NIC) I, II y III o carcinoma in situ (CIS) (23). La NIC I regresa en cerca del 70 $\%$ de los casos $(24,25)$, por eso se considera como de bajo grado. La tasa de progresión de la neoplasia intraepitelial cervical oscila entre el 6-34\%, dependiendo de las condiciones de cada país (estrategias de detección precoz o estándares de atención sanitaria) y condiciones socio-culturales (24-26).

Siendo la infección por VPH, considerada como causa necesaria, pero no suficiente, para producir el cáncer de cuello uterino $(27,28)$; es conocido que el tipo 16 responde por el 50-60 $\%$ de los casos de cáncer cervical, mientras el tipo 18, con el 10-12 \% (29). En ausencia de una terapia óptima para el tratamiento del VPH, y conociendo que la mayoría de personas que se infectan, logran eliminar el virus de forma espontánea, tras un periodo de varios meses (1 a 2 años), regresando a la normalidad (30); se diseñó este estudio con el objetivo de evaluar la eficacia y seguridad del policresuleno en el aclaramiento del virus del papiloma humano en mujeres de 30 o más años, del Eje Cafetero, que reportaron lesión escamosa intraepitelial de bajo grado (LEI-BG), positivas para VPH, a través de colposcopía, biopsia y tamizaje.

\section{MATERIALES Y MÉTODOS}

Diseño y población. Ensayo clínicoaleatorizado, controlado, triple ciego, al que ingresaron mujeres mayores de 30 años que no estaban en la menopausia, a las cuales se les diagnosticó la presencia del VPH a través de citología cérvicovaginal, colposcopía, biopsia y positivas para VPH (16 y 18) mediante tamizaje, que fueron remitidas de la consulta externa. Entre el 01 de mayo de 2017 y el 30 de abril de 2019 en tres clínicas universitarias de referencia ubicadas en el Eje Cafetero (en las ciudades de Armenia, Pereira y Manizales), Colombia. Se excluyeron las gestantes, antecedentes de conización, NIC II o NIC III, infecciones vaginales, VIHseropositivas, antecedente de $\mathrm{VPH}$ y las que no desearon participar. Se calculó una muestra de 385 participantes suponiendo como población base la población de mujeres del Eje Cafetero, con una heterogeneidad del 50\%, nivel de confianza del $95 \%$ y un margen de error del $5 \%$. Se aplicó aleatorización por computador para selección de las mujeres participantes. La muestra se incrementó para prever las pérdidas.

Procedimiento. Uno de los médicos investigadores identificó los CIE-10 (N87.0 Displasia cervical leve) relacionado con la lesión escamosa intraepitelial de bajo grado (LEI-BG) y el virus del papiloma humano (VPH), en el periodo de estudio (sin exceder la primera semana de hecho el diagnóstico). A partir de ahí se exploró la historia clínica de la paciente, de donde se tomó la información evaluada. Tres médicos generales verificaron los criterios 
de elegibilidad y buscaron la información de los datos socio-demográficos, clínicos y quirúrgicos. Las mujeres con lesión escamosa intraepitelial de bajo grado (LEI-BG), fueron llevadas a colposcopia, biopsia y tamizaje para VPH. El diagnóstico microbiológico, de la infección por el virus del papiloma humano fue confirmado mediante HPV Direct Flow Chip; el cual permite la detección delVPHy el genotipado de 36 tipos de virus del papiloma humano de alto riesgo y bajo riesgo. El resultado fue leído por un médico capacitado para este ejercicio.

Las mujeres elegidas fueron asignadas a uno de dos grupos, mediante números aleatorios generados por computadora, para la creación de una secuencia de asignación aleatoria. Las pacientes se asignaron al grupo «1» (Policresuleno) y al grupo «2» (Lubricante vaginal a base de agua / placebo). Los códigos de aleatorización fueron depositados individualmente, en sobres cerrados y opacos, los cuales se abrieron después de que cada mujer aceptó ser incluida y firmó, de manera voluntaria, el consentimiento informado. Una enfermera profesional, líder del equipo de enfermería, mantuvo bajo su custodia los sobres y fue encargada de asignar las participantes a cada grupo de la investigación. Las moléculas se presentaron de tal forma que fueran fácilmente enmascarables, trasladándose el gel comercial a un envase homogéneo para los dos productos, marcado para la investigación. El policresuleno utilizado fue el Fitoplus ${ }^{\circledR}$ gel vaginal al 1,8\%, el lubricante fue $\mathrm{K}-\mathrm{Y} \circledast$ gel vaginal. La medicación fue preparada por el suministrador en un tubo colapsible laminado de plástico por 50 gramos con 10 aplicadores vaginales (todos similares), identificados con los números «1» y «2». Los tubos, una vez preparados y etiquetados con el nombre de cada participante, fueron entregados por el regente de farmacia. Este los administró hasta el final del estudio, de tal forma que tanto el médico tratante, así como la enfermera y la participante, ignoraron la composición del tubo que se estaba usando. El enmascarado se hizo tanto a los profesionales que evaluaron los desenlaces como a quien realizó el análisis estadístico, garantizándose así un triple adecuado cegamiento. Posteriormente se le entregaba al especialista en bioestadística, el formato de recolección de datos, previamente evaluado y aprobado por el Comité de ética e investigaciones, ya diligenciados y entregados por la paciente.

Intervención.

De las 416 participantes, 207 hicieron parte del grupo «1» (policresuleno) y 209 del grupo «2» (placebo). Dosificación:

Grupo policresuleno: Se aplicó 5 gramos de policresuleno (equivalente a $90 \mathrm{mg}$ ) al día, durante diez días, y se continuó cada 3 día durante 12 semanas; por vía intravaginal. Grupo placebo (lubricante vaginal): Se aplicó 5 gramos de lubricante vaginal al día, durante diez días, y se continuó cada 3 día durante 12 semanas; por vía intravaginal.

Las pacientes fueron citadas a control cada 4 semanas después de la primera dosis hasta completar el tratamiento. A los 12 meses se les hacía colposcopía y tamizaje para VPH.

La eficacia de la intervención fue valorada según las siguientes observaciones: a) Curación: negativización en la colposcopia y el tamizaje para VPH. b) Fracaso: persistencia del VPH en la colposcopia y el tamizaje para VPH.

La seguridad se evaluó con los siguientes parámetros: a) Excelente: no se presentaron efectos adversos; b) Buena: presencia de dos a tres efectos adversos; c) Regular: presencia de tres a cinco efectos adversos; d) Pobre: presencia de efectos adversos que ameritaron la suspensión de la sustancia.

Las variables medidas: socio-demográficas (edad, etnia, nivel de escolaridad, estrato socio-económico, estado civil, ocupación, 
afiliación al sistema general de seguridad social en salud, condición espiritual o religiosa, área de residencia); variables de salud sexual y reproductiva (edad de la menarquia, embarazos, abortos, paridad, método de anticonceptivo); variables de comportamiento sexual (orientación sexual, edad de la primera relación sexual, coito -vaginal o anal-, sexo oral, frecuencia promedio de relaciones sexuales semanales, número de parejas sexuales, tiempo de convivencia en pareja, uso de juguetes eróticos y antecedentes de ITS); antecedentes personales; hábitos (tabaquismo, ingesta de alcohol, consumo de sustancias psicoactivas). Se evaluó la eficacia y seguridad del policresuleno, y se determinó la incidencia de eventos adversos. Adicional a ello se evaluó la prevalencia de los genotipos 16 y 18 del VPH y las manifestaciones clínicas de la infección por VPH. La información se digitó en Microsoft Excel 14.0, aplicándose validación de datos en las celdas para evitar errores de digitación.

Análisis estadístico. Las variables nominales cualitativas se resumieron en frecuencias absolutas y relativas, las variables cuantitativas se describen con medidas de tendencia central y dispersión, según su distribución mediante la prueba de Kolmogorov-Smirnov.

Aspectos éticos.

En la elaboración de este estudio, se tuvo en cuenta la Declaración de Helsinki, donde se establecen los principios éticos para las investigaciones médicas en seres humanos. También se consideró la Resolución 8430 de
1993 del Ministerio de Salud de la República de Colombia, la cual determina las normas científicas, técnicas y administrativas para la investigación en salud en el país. Se garantizó tantola confidencialidad, comoel anonimatoy la privacidad de la información de las participantes.

\section{RESULTADOS}

En el período de seguimiento, fueron atendidas 38.759 mujeres por condiciones no obstétricas. De estas, 8139 (20,99\%) mujeres resultaron positivas para el $\mathrm{VPH}$, de las cuales 2.538 se excluyeron por estar en el climaterio, 627 por no disponer de datos completos en la historia clínica, 1794 por antecedentes de conización, NIC II o NIC III, 1536 por presencia de infecciones vaginales, y 135 no desearon participar. De las 1509 pacientes elegibles, 361 se embarazaron, 323 se mudaron de la región, 274 no se hicieron los tres estudios, 135 no volvieron al control de los 12 meses, de tal manera que para el final del estudio se contó con un total de 416 participantes.

La edad media de la población estudiada fue de 34,62 $\pm 10,89$ años. El 75,48\% procedían del área urbana, el 86,77\% eran católicas, el $92,78 \%$ se declararon heterosexuales, el $83,89 \%$ pertenecían al aseguramiento contributivo de los trabajadores en el sistema general de seguridad social en Colombia. Las características sociodemográficas se describen en la tabla 1. 


\begin{tabular}{|c|c|c|c|}
\hline Variables & $\begin{array}{c}\text { Grupo } 1 \\
n=207\end{array}$ & $\begin{array}{c}\text { Grupo } 2 \\
n=209\end{array}$ & $p$ \\
\hline Edad (años), promedio (DE) & $35,11 \pm 10,75$ & $34,98 \pm 10,48$ & 0,567 \\
\hline Talla, mts & $158,42 \pm 0,16$ & $159,38 \pm 0,23$ & 0,582 \\
\hline Peso, $\mathrm{Kg}$ & $60,25 \pm 7,16$ & $61,02 \pm 6,97$ & 0,498 \\
\hline IMC, Kg/m2, promedio (DE) & 24,15 & 24,32 & 0,492 \\
\hline \multicolumn{4}{|l|}{ Raza } \\
\hline Hispánicas & $71,98 \%(149)$ & $73,68 \%(154)$ & 0,816 \\
\hline Afro descendientes & $25,12 \%(52)$ & $23,92 \%(50)$ & 0,255 \\
\hline Indígenas & $2,89 \%(6)$ & $2,39 \%(5)$ & 0,153 \\
\hline \multicolumn{4}{|l|}{ Estado civil } \\
\hline Casada / Unión libre & $48,79 \%(101)$ & $50,71 \%(106)$ & 0,357 \\
\hline Soltera & $34,29 \%(71)$ & $30,62 \%(64)$ & 0,166 \\
\hline Divorciada & $11,59 \%(24)$ & $12,44 \%(26)$ & 0,783 \\
\hline Viuda & $5,31 \%(11)$ & $6,22 \%(13)$ & 0,534 \\
\hline \multicolumn{4}{|l|}{ Nivel de escolaridad } \\
\hline Primaria & $8,21 \%(17)$ & $9,56 \%(20)$ & 0,873 \\
\hline Secundaria & $50,24 \%(104)$ & $53,58 \%(112)$ & 0,477 \\
\hline Técnica & $24,63 \&(31)$ & $16,74 \%(35)$ & 0,144 \\
\hline Profesional & $26,57 \%(55)$ & $20,09 \%(42)$ & 0,624 \\
\hline \multicolumn{4}{|l|}{ Ocupación } \\
\hline Amas de casa & $45,41 \%(94)$ & $46,88 \%(98)$ & 0,774 \\
\hline Empleadas & $42,99 \%(89)$ & $43,54 \%(91)$ & 0,771 \\
\hline Desempleadas & $2,41 \%(5)$ & $1,43 \%(3)$ & 0,864 \\
\hline Pensionadas & $9,17 \%(19)$ & $8,13 \%(17)$ & 0,708 \\
\hline \multicolumn{4}{|l|}{ Estrato socio-económico } \\
\hline Alto & $12,56 \%(26)$ & $14,83 \%(31)$ & 0,816 \\
\hline Medio & $63,76 \%(132)$ & $64,59 \%(135)$ & 0,924 \\
\hline Bajo & $23,67 \%(49)$ & $20,57 \%(43)$ & 0,735 \\
\hline
\end{tabular}


reportó una media de 11,37 $\pm 2,58$ años, el promedio de la edad de inicio de las relaciones sexuales fue de 14,85 $\pm 1,37$ años. El 89,42\% de las mujeres habían estado embarazadas, el $43,99 \%$ habían tenido al menos un parto, el $18,75 \%$ tenían tres o más hijos, y el 6,49\% refirió abortos previos (el 2,88\% dijo haber tenido abortos inducidos); encontrándose una mediana de 4 embarazos (rango entre 0 y 9), la mediana de hijos reportó 2 (rango entre 1 y 6). La edad en que se embarazaron por primera vez reportó una media de 18,42 \pm 1,47 años.

En cuanto al uso de métodos anticonceptivos, el $35,33 \%$ no planificaba, el $10,81 \%$ utilizaba métodos de emergencia, el 33,17\% usaba anticonceptivos orales, el $15,14 \%$ tenía el implante subdérmico, el 5,52\% restante usaba métodos de barrera. El 19,47\% ( $n=81 / 416)$ refirió el antecedente de, por lo menos una, ITS (herpes genital: 56,79\%, sífilis: 12,34\%, gonorrea: 11,11\%, tricomoniasis: $4,93 \%$, y Chlamydia trachomatis: 2,46\%, otro $12,34 \%$ no recordaba el tipo de ITS).

Respecto al número de parejas sexuales, el 71,39\% afirmó haber tenido entre 3 y 9 parejas sexuales a lo largo de su vida; en el último año, el 28,12\% refirió contacto con una única pareja sexual. La mediana de parejas sexuales, en la población total, fue de 5 (rango entre $1 y \geq 15$ ). El tiempo de vida sexual activa arrojó una media de 11,58 \pm 3,57 años.

El 59,85\% de las participantes expresó tener relaciones sexuales entre 2 y 5 veces a la semana, con una mediana de 3 (rango entre 0 y 7). El tiempo de convivencia en pareja reportó una media de 7,86 \pm 3,54 años.

Las prácticas sexuales reportaron que el $100 \%$ de las mujeres practicaba sexo vaginal, el $85,81 \%$ sexo oral y el $29,56 \%$ sexo anal. El uso de juguetes eróticos o sexuales fue reportado por el $41,82 \%$ de las participantes.

Con relación a los hábitos, el 20,91\% eran fumadoras, el $5,76 \%$ consumía sustancias psicoactivas y el $91,58 \%$ ingería alcohol de forma regular.

El genotipo prevalente del VPH fue el 16 con un $59,13 \%(n=246)$ frente al $40,86 \%(n=170)$ del genotipo 18. La prevalencia combinada de los genotipos 16 y 18, fue del 26,68\% $(n=111)$. Las manifestaciones clínicas en las mujeres participantes se caracterizaron por leucorrea $(44,95 \%)$ y la presencia de ectropión (39,42\%).

\begin{tabular}{|l|c|}
\hline \multicolumn{2}{|c|}{$\begin{array}{c}\text { Tabla 2. Manifestaciones clrnicas en mujeres con LEI-BG, en } \\
\text { mujeres del Eje Cafetero, 2017-2019 }\end{array}$} \\
\hline \multicolumn{1}{|c|}{ Manifestaciones } & $\mathbf{n ~ ( \% )}$ \\
\hline Comezón - Picazón & $44(10,57)$ \\
\hline Dispareunia & $23(5,52)$ \\
\hline Ectropión & $164(39,42)$ \\
\hline Irritación cervical & $74(17,78)$ \\
\hline Leucorrea & $187(44,95)$ \\
\hline Prurito vulvo-vaginal & $37(8,89)$ \\
\hline Sinusorragia & $64(15,38)$ \\
\hline
\end{tabular}


A los 12 meses se observó que en el grupo del policresuleno, lanegativizacióndelacolposcopia y el tamizaje del VPH, alcanzó el 89,85\%, frente al 64,59\% del grupo placebo, diferencia estadísticamente significativa $\quad(p<0,001)$.

Las mujeres sin hijos reportaron una mayor negativización en el grupo del policresuleno, con el 92,68\% frente al $70,73 \%$ del grupo placebo, diferencia estadísticamente significativa $\quad(p<0,001)$.

Las mujeres que reportaron una sola pareja sexual arrojaron una negativización del $95,65 \%$ en el grupo del policresuleno, frente al $73,91 \%$ del grupo placebo, diferencia estadísticamente significativa $\quad(p<0,001)$.
Las mujeres sin hijos y que reportaron una sola pareja sexual, presentaron un aclaramiento del VPH del 97,91\% en el grupo del policresuleno, frente al 76,04\% del grupo placebo, diferencia estadísticamente significativa $\quad(p<0,001)$.

El efecto adverso que se presentó con más frecuencia, en el grupo policresuleno, fue la sequedad vaginal $(7,24 \%)$ y la descarga de fragmentos de membrana mucosa (8,69\%), en especial durante la primera semana; su incidencia fue del $6,69 \%$ y $8,13 \%$ en el grupo placebo, respectivamente, sin diferencia estadísticamentesignificativa $(p=0,051)$ (tabla 3$)$.

\begin{tabular}{|l|c|c|c|}
\hline \multicolumn{4}{|c|}{$\begin{array}{c}\text { Tabla 3. Efectos adversos en mujeres con LEI-BG, Eje } \\
\text { Cafetero, Colombia, 2017-2019 }\end{array}$} \\
\hline \multicolumn{1}{|c|}{ Efectos adversos } & $\begin{array}{c}\text { Policresuleno } \\
\mathrm{n}(\%)\end{array}$ & $\begin{array}{c}\text { Placebo } \\
\mathrm{n}(\%)\end{array}$ & Valor $\mathrm{p}$ \\
\hline Ardor vaginal & $13(6,28)$ & $11(5,26)$ & $>0,05$ \\
\hline Candidiasis vaginal & $9(4,34)$ & $12(5,74)$ & $>0,05$ \\
\hline $\begin{array}{l}\text { Descarga de fragmentos } \\
\text { de membrana mucosa }\end{array}$ & $18(8,69)$ & $17(8,13)$ & $>0,05$ \\
\hline Prurito vulvar & $11(5,31)$ & $8(3,82)$ & $>0,05$ \\
\hline Sequedad vaginal & $15(7,24)$ & $14(6,69)$ & $>0,05$ \\
\hline
\end{tabular}

DLa seguridad de las sustancias fue definida como excelente, buena y regular en el $87,92 \%, 10,14 \%$ y $1,93 \%$ respectivamente en el grupo policresuleno, frente al $88,99 \%$, $10,04 \%$ y $0,95 \%$ en el grupo placebo ( $p>0,05)$, y no se reportó ninguna complicación. Tampoco hubo necesidad de suspender el producto en ninguna de las participantes.

Se encontraron diferencias respecto a los grupos (en las pacientes sintomáticas) en la presencia de leucorrea persistente $[22,96 \%$ (grupo placebo) vs 5,79\% (grupo policresuleno); $\mathrm{p}=$ $0,003]$ y prurito vulvo-vaginal [27,53\% (grupo placebo) vs 10,14\% (grupo policresuleno); $p=0,012]$. No se encontraron asociaciones entre el producto recibido y la presencia de candidiasis vaginal: $4,34 \%$ con policresuleno frente al $5,74 \%$ del placebo $(p=0,714)$.

\section{Discusión}

Se ha confirmado que existen hasta 16 genotipos oncogénicos del VPH, de los cuales el 16 y 18 están relacionados causalmente con la mayoría de los cánceres de cérvix a nivel mundial. El 
VPH 16 y 18, son causantes del $72 \%$ de todos los cánceres de cuello uterino en España; y por orden de frecuencia, los genotipos 16, 18, 45, $31,33,52$ y 58 son globalmente responsables de más del $85 \%$ de los casos $(21,31)$. Las características de la historia natural de la infección por VPH también se relacionan con el tipo viral. El grupo de alto riesgo neoplásico tiende a establecer infecciones persistentes y a progresar con mayor frecuencia que el grupo de tipos de bajo riesgo $(21,24)$. La duración media estimada de las infecciones por virus de alto riesgo es de 8-12 meses, mientras que las infecciones por los genotipos 16 ó 18, tienden a persistir por períodos más prolongados (16-24 meses) $(24,25,31)$.

El policresuleno ha mostrado utilidad en el manejo del virus del papiloma humano $(32,33)$. El éxito del producto, en el tratamiento del VPH, hace parte de un factor coadyuvante con efecto sobre la infección coilocítica; por lo tanto, conociendo las propiedades queratolíticas y queratoplásticas de la molécula $(34,35)$, resulta totalmentelógico intentarel manejo conjunto del LEI-BG positivo para VPH, con el policresuleno, a fin de lograr su rápido aclaramiento.

En la actualidad, no existe un tratamiento satisfactorio para el tratamiento rápido y no invasivo de las displasias del cérvix, tipo lesión escamosa intraepitelial de bajo grado (LEI-BG) positivas para $\mathrm{VPH}$, por lo que los especialistas usualmente permiten que la infección corra su curso hasta la negativización. Ante esta situación, las mujeres se enfrentan a considerables limitaciones en el estilo de vida, en especial con respecto al uso de instalaciones públicas (baños, gimnasios, piscinas, etc.) o a la misma actividad sexual, debido a la elevada capacidad de infección del virus, así como por los efectos psicológicos y sociales que le impone sentirse infectadas por el VPH.

En el presente estudio, se mostró que la negativización del VPH (aclaramiento), alcanza hasta el $89,85 \%$ de las mujeres en el grupo del policresuleno. Por lo cual, se establece la molécula como un producto a tener en cuenta en el grupo poblacional de mujeres mayores de 30 años a las cuales se les diagnostica la presencia del VPH en la biopsia de cérvix cuando presentan LEI-BG.

El policresuleno puede ser una buena alternativa terapéutica en mujeres con LEIBG positivas para $\mathrm{VPH}$, ya que resultó eficaz, fácil de aplicar, se puede autoadministrar con efectos secundarios mínimos. No obstante, no existe suficiente evidencia al respecto, y los pocos estudios publicados sobre el tema no proporcionan datos definitivos.

La similitud en la frecuencia de efectos adversos, fue observada en las dos poblaciones de mujeres participantes. De esta manera, el excelente nivel de seguridad del policresuleno, y la adecuada aceptación por parte de las pacientes, resultó en la minimización de las deserciones y, por lo tanto, en la rápida negativización o aclaramiento del LEI-BG.

Los resultados de este ensayo clínico, harán posible pensar en el policresuleno como una potencial opción terapéutica en el manejo del LEI-BG, en mujeres positivas para VPH, siendo posible evaluar todos estos aspectos de su utilización, ante la efectividad y seguridad demostrada. Además de hacer posible que la mayoría de los casos puedan beneficiarse de este tratamiento, desde la atención primaria hasta el más alto nivel de complejidad, lo cual ayudaría a disminuir las referencias a especialistas, algunas veces innecesarias.

Entre las limitaciones de este estudio se encuentra que no se reclutaron participantes con otros genotipos de alto riesgo, a menos que acompañaran a los 16 y 18; sin embargo, no creemos que esto pueda generar un resultado diferente. En segundo lugar, no se puede establecer o atribuir la causalidad de 
curación, de forma exclusiva, al policresuleno.

Una fortaleza de este estudio, radica en ser el primero en su diseño, hasta la fecha. Lo segundo es lo grande del tamaño de la muestra, lo que puede ayudar a alcanzar significación estadística en los resultados obtenidos. Sin embargo, los resultados de esta investigación deben considerarse con precaución, ya que se involucraron mujeres con un alto potencial de curación espontánea. Estudios futuros se hacen necesarios, principalmente para evaluar, más a fondo, la significativa tasa de curación reportada.

\section{Conclusiones}

La mejoría del 89,85\% de la lesión escamosa intraepitelial de bajo grado (LEI-BG) positivas para $\mathrm{VPH}$, en mujeres mayores de 30 años, asociada a baja frecuencia de efectos adversos, significa que el uso del policresuleno es una efectiva y segura opción terapéutica. Si bien se evidenció la presencia de efectos adversos, estos fueron tolerables y no ameritaron el retiro de la terapia en ningún caso. Es indispensable individualizar a cada mujer en particular, a fin de evaluar los factores de riesgo, potencialmente corregibles, para no dejar la falsa expectativa de que el policresuleno hará la milagrosa cura.

\section{Financiamiento}

El autor no recibió patrocinio para llevar a cabo este estudio. Se realizó con recursos propios, obtenidos de los turnos de obstetricia.

\section{Agradecimientos}

A mi colega, maestro y amigo, el doctor Daniel De León Ospina, por sus enriquecedoras sugerencias en la elaboración y revisión de esta investigación; a Hathor, Clínica Sexológica, por facilitar sus instalaciones para la tabulación y diagramación.

\section{REFERENCIAS}

1) Zur Hausen H. Papillomaviruses causing cancer: Evasion from host-cell control in early events in carcinogenesis. J Natl Cancer Inst. 2000; 92(9):690-8. http://dx.doi.org/10.1093/jnci/92.9.690.

2) Stanley M, Lowy DR, Frazer I. Chapter 12: Prophylactic HPV vaccines: Underlying mechanisms. Vaccine. 2006; 116(5):116773. http://dx.doi.org/10.1172/JCl28607

3) Stanley MA. Genital human papillomavirus infections: Current and prospective therapies. J Gen Virol. 2012; 93:681-91 http://dx.doi.org/10.1099/vir.0.039677-0

4) Grillo-Ardila CF, Martínez-Velásquez MY, Morales-López B. Virus del papiloma humano: aspectos moleculares y cáncer de cérvix. Rev Colomb Obstet Ginecol. 2008; 59(4):310-15.

5) Ho GY, Bierman R, Beardsley L, Chang CJ, Burk RD. Natural history of cervicovaginal papillomavirus infection in young women. N Engl J Med 1998; 338:423-28. http:// dx.doi.org/10.1056/NEJM199802123380703.

6) Al Moustafa AE, Al-Awadhi R, Missaoui N, Adam I, Durusoy R, Ghabreau L, A et al. Human papillomaviruses-related cancers. Presence and prevention strategies in the Middle east and north African regions. Hum. Vaccines Immunother. 2014; 10(7):181221. http://dx.doi.org/10.4161/hv.28742

7) Al Moustafa AE, Al-Antary N, Aboulkassim T, Akil N, Batist G, Yasmeen A. Coprevalence of Epstein-Barr virus and highrisk human papillomaviruses in Syrian women with breast cancer. Hum. Vaccines Immunother. 2016; 12(7):1936-9. http:// dx.doi.org/10.1080/21645515.2016.1139255

8) León D, Retamal J, Silva R, Ili C, Mieville S, Guzmán P, et al. Detección molecular de agentes infecciosos de transmisión sexual en un grupo de hombres sintomáticos y su relación con la conducta sexual. Rev Chilena 
Infectol 2016; 33(5):505-12. http://dx.doi. org/10.4067/S0716-10182016000500003

9) Rodríguez González D, Pérez Piñero J, Sarduy Nápoles M. Infección por el virus del papiloma humano en mujeres de edad mediana y factores asociados. Rev Cuba Obstet Ginecol. 2014; 40(2):218-32.

10) Parkin DM, Bray F. CChapter 2: The burden of HPV-related cancers. Vaccine $24 S 3$ (2006) S3/11-S3/25. http://dx.doi. org/10.1016/j.vaccine.2006.05.111 11) D'Souza G, Kreimer AR, Viscidi R, Pawlita M, Fakhry C, Koch WM. Case-control study of human papillomavirus and oropharyngeal cancer. N Engl J Med. 2007; 356(19):1944-56.

12) Smith JS, Lindsay L, Hoots B, Keys J, Franceschi S, Winer R, Clifford GM. Human papillomavirus type distribution in invasive cervical cancer and highgrade cervical lesions: a meta-analysis update. Int J Cancer. 2007; 121(3):621-32. http://dx.doi.org/10.1002/ijc.22527

13) Bosch FX, Qiao YL, Castellsagué X. The epidemiology of human papillomavirus infection and its association with cervical cáncer International Journal of Gynecology and Obstetrics. 2006; 94 (Supplement 1): S8-S21

14) Rey-Ares L, Ciapponi A, Pichon-Riviere Andrés.Efficacy and safety of human papilloma virus vaccine in cervical cancer prevention: systematic review and meta-analysis. Arch. argent. pediatr. 2012; 110(6):483-9.

15) Vega-Malagón G, Ávila-Morales J, GarcíaSolís P, Camacho-Calderón N, Becerril-Santos A, Vega Malagón AJ, et al. Infección por el virus del papilomahumano.Biologíamolecular. European Scientific Journal. 2014; 10(18):352-62.

16) Serena-Gómez E, Bologna-Molina RE, Nevarez-RasconA, RochaBuelvasA. Prevalencia del VPH en el Proceso de Malignización de Lesiones de Vías Aérodigestivas Superiores. Int J Odontostomat. 2011; 5(1):5-12.

17) Baseman JG., Koutsky LA. The epidemiology of human papillomavirus infections. J. Clin. Virol. 2005; 32(Suppl. 1):S16-S24. http:// dx.doi.org/10.1016/j.jcv.2004.12.008

18) Aguilar-Lemarroy A, Vallejo-Ruiz V, Cortés-Gutiérrez El, Salgado-Bernabé ME, Ramos-González NP, Ortega-Cervantes L. (2015). Human papillomavirus infections in Mexican women with normal cytology, precancerous lesions, and cervical cancer: Type-specific prevalence and HPV coinfections. J Med Virol. 2015; 87(5):87184. http://dx.doi.org/10.1002/jmv.24099

19) Salcedo $M$, Pina-Sanchez $P$, VallejoRuiz V, Monroy-Garcia A, Aguilar-Lemarroy A, Cortes-Gutierrez El, et al. Human Papillomavirus Genotypes among Females in Mexico: a Study from the Mexican Institute for Social Security. Asian Pac J Cancer Prev. 2015; 15(23):10061-6. http://dx.doi. org/10.7314/APJCP.2014.15.23.10061

20) ACOG Practice Bulletin \#61: Human Papillomavirus. Obstet Gynecol. 2005; 105(4):905-18. http://dx.doi. org/10.1097/00006250-200504000-00056

21) Muñoz N, Bosch FX, de Sanjosé $S$, Herrero R, Castellsagué X, Shah KV, et al. Epidemiologic Classification of Human Papillomavirus Types Associated with Cervical Cancer. N Engl J Med. 2003; 348(6):518-27. http://dx.doi.org/10.1056/NEJMoa021641

22) Carrillo-Pacheco A, HernándezValencia $M$, Hernández-Quijano $T$, Zárate A. Modalidades terapéuticas en infección por virus del papiloma humano. Ginecol Obstet Mex 2012; 80(11):712-9. ebectrocautexización.de lastesidempe ptremal ignars 
del cérvix. Colomb Med. 1995; 26:119-24. 24) Hartwig S, Baldauf JJ, Dominiak-Felden G, Simondon F, Alemany L, de Sanjose S, et al. Estimation of the epidemiological burden of HPV-related anogenital cancers, precancerous lesions, and genital warts in women and men in Europe: Potential additional benefit of a nine-valent second generation HPV vaccine compared to first generation HPV vaccines. Papillomavirus Research. 2015; 1:90-100. https://doi.org/10.1016/j.pvr.2015.06.003.

25) Hellberg D, Nilsson S, Valentin J. Positive Cervical Smear with Subsequent Normal Colposcopy and HistologyFrequency of CIN in a Long-Term Followup. Gynecol Oncol. 1994; 53(2):148-5. http://dx.doi.org/10.1006/gyno.1994.1107

26) Ostör AG. Natural History of Cervical Intraepithelial Neoplasia: A Critical Review. Int J Gynecol Pathol. 1993; 12(2):186-92.

27) Walboomers JM, Meijer CJ. Do HPVnegative Cervical Carcinomas Exist? J Pathol. 1997; 181(3):253-4. http://dx.doi.org/10.1002/ (SICI)1096-9896(199703)181:3<253::AID$\mathrm{PA} \mathrm{TH} 755>3$. 5 . $\mathrm{C} \mathrm{O} ; 2-0$

28) González-Sánchez JL, Flores-Avilés Y, Gómez-Campos G, Montero-Ramírez A. Asociación de Chlamydia trachomatis y virus del papiloma humano comofactores predisponentes en la etiopatogenia de la neoplasia intraepitelial cervical. Obstet Ginecol Mex. 1995; 63:422-6.

29) Bosch FX, de Sanjose S. Chapter 1: Human Papillomavirus and Cervical Cancer--Burden and Assessment of Causality. J Natl Cancer Inst Monogr. 2003; (31):3-13. http://dx.doi.org/10.1093/ oxfordjournals.jncimonographs.a003479
30) American Academy of Pediatrics. Human Papillomaviruses. En: Kimberlin DW, ed. Red Book:2015Report of theCommitteeon Infectious Diseases. 30thed. Elk GroveVillage, IL:American Academy of Pediatrics; 2015. págs. 576-83.

31) Alemany L, Pérez C, Tous S, LlombartBosch A, Lloveras B, Lerma E, et al. Human Papillomavirus Genotype Distribution in Cervical Cancer Cases in Spain. Implications for Prevention. Gynecol Oncol. 2012; 124(3):512-7. http:// dx.doi.org/10.1016/j.ygyno.2011.11.024

32) Pérez-Salazar J, Diaz-Loya F, el al. The trichomonicidal fungicidal and bactericidal effect of metacresolsulphonic acid methanal polymer in cervicovaginitis. Ginecología y Obstetricia de México. 1983; 51(3):10.

33) Medina-Angulo D, Fúster-Alfaro F. Eficacia en vaginosis bacteriana $y$ control de HPV aplicando Albothylr y ac. metracresolsulfonico. Revista Médica de Costa Rica y Centroamérica LXIII. 1996; 535: 57-61.

34) Espitia-De La Hoz FJ. Efficacy and tolerance of policresulen in the treatment of the genitourinary syndrome of menopause. Int J Fam Commun Med 2019; 3(3):132-6. https://doi.org/10.15406/ijfcm.2019.03.00145

35) Espitia-De-La-Hoz F. Efectividad y seguridad del policresuleno en el tratamiento del síndrome genitourinario de la menopausia. Estudio controlado y aleatorizado. Arch Med (Manizales) 2020; 20(2):en prensa. https://doi.org/10.30554/archmed.20.2.3756 